\title{
Non-invasive preoperative assessment of ureteral stone impaction using peri-calculus ureteral thickness on Non-Contrast CT (NCCT) scan: A prospective Study
}

\author{
K Sharma P. ${ }^{1 *}$, Aggarwal V. ${ }^{2}$, Baweja S. ${ }^{3}$, Nagori R. ${ }^{4}$, Katti P. ${ }^{5}$, Chhabra M. ${ }^{6}$ \\ DOI: https://doi.org/10.17511/ijoso.2020.i02.01 \\ 1* Pradeep K Sharma, Associate Professor, Department of Urology, Dr. SN Medical College, Jodhpur, Rajasthan, India. \\ 2 Vikas Aggarwal, Resident, Department of Urology, Dr. SN Medical College, Jodhpur, Rajasthan, India. \\ 3 Shekhar Baweja, Resident, Department of Urology, Dr. SN Medical College, Jodhpur, Rajasthan, India. \\ ${ }^{4}$ Rupesh Nagori, Resident, Department of Urology, Dr. SN Medical College, Jodhpur, Rajasthan, India. \\ $\mathbf{5}$ Pawan Katti, Resident, Department of Urology, Dr. SN Medical College, Jodhpur, Rajasthan, India. \\ 6 M K Chhabra, Professor, Department of Urology, Dr. SN Medical College, Jodhpur, Rajasthan, India.
}

Background: Ureteral stone can be measured on the NCCT scan as peri-calculus ureteral thickness. If this depicts significant calculus impaction, the patient could be counseled regarding intra-operative risk and incomplete stone clearance. The present study was planned to evaluate the use of NCCT in patients with ureterolithiasis for the prediction of a favorable clinical outcome. Materials and methods: Patients who underwent ureterorenoscopy for ureteric calculus with pre-operative NCCT scan were included and intraoperative data were recorded. Operating surgeons were blinded for proximal ureteric wall thickness ( $p$-UWT), peri-calculus ureteric wall thickness ( $p$-CUT), and distal ureteric wall thickness (d-UWT) values. The guidewire was negotiated before each URS. Stone was considered impacted if guidewire could not be negotiated in 2 attempts. Results: Of total patients 108 patients, 70 patients had non-impacted calculus and 38 patients had impacted calculus. Patients with an impacted calculus had significantly higher p-UWT $(9.76 \pm 3.11 \mathrm{~mm}), \mathrm{p}-\mathrm{CUT}(6.82 \pm 2.57 \mathrm{~mm})$, and $d$-UWT $(6.26 \pm 2.28 \mathrm{~mm})$ as compared to non-impacted. There was a positive correlation in SIS with p-UWT, p-CUT, and p-DWT in both impacted and non-impacted groups. Conclusion: Preoperative ureteric wall thickness in proximal, peri, and distal to calculus can predict intraoperative risk and impaction of calculus.

Keywords: Ureteric thickness, Ureteral stone, NCCT, Stone impaction

Corresponding Author

Pradeep K Sharma, Associate Professor, Department of Urology, Dr. SN Medical College, Jodhpur, Rajasthan, India.

Email: dr.pradeepsharma261@gmail.com

\section{How to Cite this Article}

Sharma PK, Aggarwal V, Baweja S, Nagori R, Katti P, Chhabra MK. Non-invasive preoperative assessment of ureteral stone impaction using peri-calculus ureteral thickness on Non-Contrast CT (NCCT) scan: A prospective Study. Surgical Review Int J Surg Trauma Orthoped. 2020;6(1):67-71.

Available From

https://surgical.medresearch.in/index.php/ijoso/artic le/view/163
To Browse

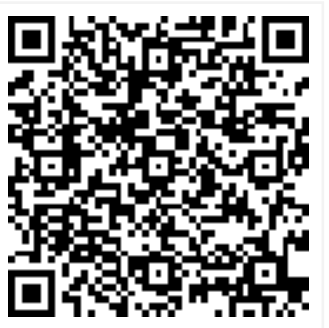




\section{Introduction}

Ureters are part of the urinary tract, and they carry urine produced by the kidneys to the bladder. Ureteral stones are kidney stones that have become stuck in one or both ureters. Ureteric stone is a common cause of acute flank pain with increasing prevalence. Ureteral stone impaction causes papillary hypertrophy and edema of ureteric transitional epithelium causing a ureteric wall to thicken [1].

Extracorporeal shockwave lithotripsy, Ureteroscopy (URS), percutaneous methods, and medical expulsive therapy are the treatment option for the ureteric stone [2,3]. Ureteroscopy (URS) has evolved into a safer and more efficacious mode of treatment for stones in all locations in the ureter $[3,4]$.

This thickened ureteric wall makes endoscopic ureteral stone surgery more challenging [5]. Preoperative, NCCT findings of perinephric fat stranding, hydronephrosis, and ureteric wall thickness, aid diagnosis of impacted ureterolithiasis [6]. Non-contrast CT (NCCT) has also been reported to be more sensitive than excretory urography for ureteral stones [7].

NCCT is a non-invasive investigation and can diagnose extra urinary causes of obstruction [8].To our knowledge, a little work has been done in the evaluation of NCCT for help in predicting a favorable clinical outcome in patients with ureteral stones. Based on the findings of NCCT, the patient could be counseled regarding intra-operative risk, incomplete clearance, or second procedure. The present study was planned to evaluate the use of NCCT in patients with ureterolithiasis for the prediction of a favorable clinical outcome.

\section{Material and Methods}

Study setting: This study was conducted in the Department of Urology, Dr. S.N. Medical College, Jodhpur in patients who underwent ureterorenoscopy for ureteric calculus with preoperative NCCT scan.

Duration and type of study: This present prospective study was conducted between January 2019 to June 2019.

Sampling methods and sample size calculation: All consecutive patients who underwent ureterorenoscopy for ureteric calculus
With a pre-operative NCCT scan were considered for this study. This was a duration based study; so all patients during the study period of six months were included in the study.

Inclusion criteria: All patients with single ureteric calculus, duration of symptoms $>2$ months, patients who underwent pre-operative NCCT, and patiently planned for URSL were included in the study.

Exclusion criteria: Patients with congenital anomalies, chronic kidney disease, previous history of ipsilateral ureteric surgery or DJ in situ, UVJ calculi, calculus pushed back into renal pelvis were excluded out from the study.

Procedure: Operating surgeons were blinded for proximal ureteric wall thickness ( $p$-UWT-distance between the inner wall and outer wall of the ureter at just proximal end of calculus), peri-calculus ureteric wall thickness(p-CUT-distance between the inner wall and outer wall of the ureter at the mid of length of calculus) and distal ureteric wall thickness (d-UWT-distance between the inner wall and outer wall of the ureter at just distal end of calculus) values. The guidewire was negotiated before each URS.

Stone was considered impacted if guidewire could not be negotiated in 2 attempts. Intra-operative stone impaction score (SIS) assigned on a scale of 0 (dislodged spontaneously), 1 (dislodged with saline pressure), 2 (dislodged after lithotripsy), 3 (fragments impacted in edema) and 4 (open). This score denotes the ease with which the surgeon can engage calculus for lithotripsy. Intra-operative findings were correlated to preoperative NCCT measurements of ureteral thickness. Other variables like duration of symptoms, hydronephrosis, stone size in the longest dimension, and stone location were also analyzed.

Ethical consideration and permission: This study was conducted only after approval from the institutional ethics committee and all patients were enrolled in the study only after taking informed consent.

Statistical Analysis: Data was recorded in 'Microsoft excel 2007' format and analyzed using SPSS version 15.0'. Impacted and non-impacted groups were compared and analyzed using the student " $t$ " test. Spearman correlation test was applied to find the relation of SIS with p-UWT, $p$ CUT, and p-DWT. A p-value of less than 0.05 was considered significant for all parameters. 


\section{Results}

In the present study as the duration of disease increases, there was a significant increase in $\mathrm{p}$-UWT, $p$-CUT, and $d$-UWT values $(p<0.001)$. The patients were also divided into groups based on the duration of symptoms into 6 monthly intervals and these groups were compared.

Significantly higher ureteric wall thickness values were found at all three levels among the groups (Table 1).

Table-1: Duration of stone in relation to $p$ UWT, p-CUT, d-UWT.

\begin{tabular}{|l|l|l|l|}
\hline \multicolumn{1}{|c|}{$\begin{array}{c}\text { Duration of } \\
\text { stone(months) }\end{array}$} & \multicolumn{1}{|c|}{$\begin{array}{c}\text { p-UWT } \\
\text { (Mean } \pm \text { SD })\end{array}$} & \multicolumn{1}{|c|}{$\begin{array}{c}\text { p-CUT } \\
(\text { Mean } \pm \text { SD })\end{array}$} & $\begin{array}{c}\text { d-UWT } \\
\text { (Mean } \pm \text { SD })\end{array}$ \\
\hline$<6$ & $3.09 \pm 1.80$ & $2.34 \pm 1.13$ & $2.26 \pm$ \\
\hline $6-12$ & $8.78 \pm 2.58$ & $6.51 \pm 2.10$ & $5.83 \pm$ \\
\hline$>12$ & $11.26 \pm 2.03$ & $7.94 \pm 1.60$ & $7.35 \pm$ \\
\hline P value & $<0.001^{*}$ & $<0.001 *$ & $<0.001^{*}$ \\
\hline
\end{tabular}

*significant

Of total patients 108 patients, 70 patients had nonimpacted calculus and 38 patients had impacted calculus. The impacted calculus group was compared to the non-impacted calculus group. A significantly higher ureteric wall thickness values were found at all three levels among the groups.

Patients with an impacted calculus had significantly higher p-UWT $(9.76 \pm 3.11 \mathrm{~mm}), \quad \mathrm{p}$-CUT $(6.82 \pm 2.57 \mathrm{~mm})$, and d-UWT $(6.26 \pm 2.28 \mathrm{~mm})$ as compared to non-impacted. $(p<0.001)$ Significantly higher duration of symptoms ( $10.20 \pm 5.15$ months) was found in the impacted group as compared to the non-impacted group (4.26 \pm 2.77 months). $(p<0.001)$ (Table 2$)$.

Table- 2: Comparison between the impacted and non-impacted stone.

\begin{tabular}{|l|l|l|l|}
\hline & \multicolumn{1}{|c|}{$\begin{array}{c}\text { Impacted } \\
\text { stone(38) }\end{array}$} & $\begin{array}{l}\text { Non-impacted stone } \\
\text { (70) }\end{array}$ & $\begin{array}{c}\text { P } \\
\text { value }\end{array}$ \\
\hline Age (years) & $31.42 \pm 14.30$ & $35.94 \pm 15.20$ & 0.135 \\
\hline Sex (M/F ratio) & $20 / 18$ & $41 / 29$ & \\
\hline BMI (kg/m2) & $24.03 \pm 3.77$ & $23.78 \pm 3.28$ & 0.949 \\
\hline $\begin{array}{l}\text { Duration of symptoms } \\
\text { (months) }\end{array}$ & $10.20 \pm 5.15$ & $4.26 \pm 2.77$ & $\begin{array}{l}<.00 \\
1 *\end{array}$ \\
\hline p-UWT $(\mathrm{mm})$ & $9.76 \pm 3.11$ & $3.62 \pm 2.27$ & $\begin{array}{l}<0.00 \\
1 *\end{array}$ \\
\hline p-CUT(mm) & $6.82 \pm 2.57$ & $2.86 \pm 1.72$ & $\begin{array}{l}0.00 \\
1 *\end{array}$ \\
\hline d-UWT $(\mathrm{mm})$ & $6.26 \pm 2.28$ & $2.69 \pm 1.52$ & $<0.00$ \\
& & & $1 *$ \\
\hline
\end{tabular}

\begin{tabular}{|l|l|l|l|}
\hline Hounsfied unit $(\mathrm{HU})$ & $895.05 \pm 372.00$ & $864.61 \pm 361.08$ & 0.616 \\
\hline Stone size $(\mathrm{mm})$ & $13.64 \pm 5.51$ & $11.49 \pm 3.87$ & 0.02 \\
\hline
\end{tabular}

*significant

On comparing SIS score with ureteric wall thickness at all three levels using the Spearman coefficient of correlation there was a positive correlation was found. As the ureteric wall thickness increases there was a significant increase in the SIS score provided by the surgeon.

The score is skewed towards the lower value in a non-impacted group and higher value was assigned in an impacted group with a non-significant difference. (Table 3, Figure 1a and 1b)

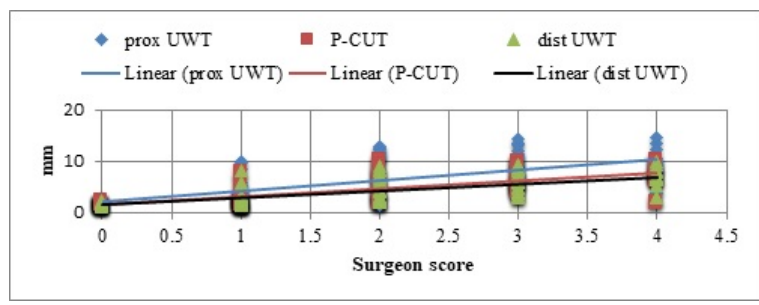

Fig-1a: Correlation of surgeon score with various findings in case of impacted stone.

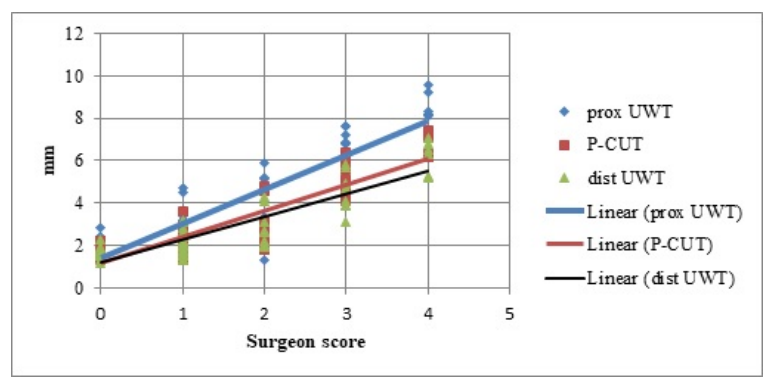

Fig-1b: Correlation of surgeon score with various findings in case of non-impacted stone.

Table 3: Correlation of surgeon score with various findings in case of impacted and nonimpacted stone.

\begin{tabular}{|l|l|l|l|l|}
\hline \multirow{2}{*}{} & \multicolumn{2}{|c|}{$\begin{array}{c}\text { Surgeon score in impacted } \\
\text { stone }\end{array}$} & \multicolumn{2}{c|}{$\begin{array}{c}\text { Surgeon score in non- } \\
\text { impacted stone }\end{array}$} \\
\cline { 2 - 5 } & $\begin{array}{l}\text { Spearman correlation } \\
\text { coefficient }\end{array}$ & P-value & $\begin{array}{l}\text { Spearman correlation } \\
\text { coefficient }\end{array}$ & P-value \\
\hline p-UWT & 0.754 & $<0.001 *$ & 0.778 & $<0.001 *$ \\
\hline$p$-CUT & 0.767 & $<0.001 *$ & 0.812 & $<0.001 *$ \\
\hline d-UWT & 0.780 & $<0.001 *$ & 0.788 & $<0.001 *$ \\
\hline
\end{tabular}

Other parameters including age, sex, body mass index, and $\mathrm{HU}$ of stone were found to have no significant relation to the ureteric wall thickness and impaction of calculus (Table 1 ). 


\section{Discussion}

NCCT is now used routinely for the diagnosis and treatment of patients with ureterolithiasis [9]. Preoperative assessments in the patients may involve invasive procedures but the advantage of using NCCT for pre-operative assessment in ureterolithiasis includes the non-invasive procedure, objective quantification of impaction, and evaluation of peri-ureteric factors. In the present study impacted stone was found significantly more as compared to non-impacted stone as the duration of symptoms increases. Ureteric wall thickness was also found more in the impacted group. Eliboletalalsofound significant correlation between the total duration of colic attacks and ureteric wall thickness [10].The reason for that could be that when stone stays in the same position for a longer time, it induces inflammatory changes in the ureteric wall. This process causes papillary edema leading to further impaction of stone [11].

Stone status in relation to ureteric wall thickness stated by Chandhoke et al observed significantly higher ureteral wall thickness above, around and below the calculus (all three $p$-values $<0.001$ ) with impacted stones as compared to none impacted stones [12]. In the present study, it was also found that significantly higher $\mathrm{p}$-UWT, $\mathrm{p}$-CUT, and p-DWTin impacted group. The inflammation, interstitial fibrosis, and urothelial hypertrophy associated with stone impaction cause ureteral edema and polyps [13].This process may involve peri-ureteric tissue also, increasing UWT around impacted calculus. The intraoperative stone impaction score in impacted calculus was also observed. Chandhoke et al used a visual-based Likert scale for degree of stone impaction intra-operatively and more than 5 was considered impacted [12].

In the present study, as p-UWT increased among the impacted stone group, intra-operative stone impaction score increased. URSL may be more difficult in impacted calculus as the edema obscures vision resulting in elevated risk of intra-operative ureteral perforation and postoperative complications. The identification of stone impaction during the diagnostic process can be a predictive variable for URSL as Legemate et al have reported higher intra-operative complication rates in impacted stone as compared with treatment for non-impacted stones [14]. No study was found to compare SIS with UWT of non-impacted calculus. In the present study; as the UWT in the non-impacted
Group increased, the SIS score was also increased. Age, sex, body mass index, did not show Similar results have shown by another study in which sex, stone location, and age did not significantly influence complications and success rates [15]. Seitz et al have also reported that age, sex, and BMI have no effect on the Efficacy of Holmium: YAG-Laser Ureterolithotripsy. But impaction of stone has an effect on its efficacy [16].

\section{Limitation}

This study was restricted to one region of India so multicentric studies with a large number of patients are needed which can give us more conclusive evidence.

\section{Conclusion}

Pre-operative ureteric wall thickness assessment, at proximal, peri, and distal to calculus on NCCT can be used to predict the impaction of calculus, intraoperative complications, and counseling the patient.

\section{What does this study add to the existing knowledge?}

This study has compared SIS with UWT of nonimpacted calculus and found that as the UWT in the non-impacted group increased, the SIS score was also increased. This comparison was not done earlier.

\section{Authors' contribution}

Dr. Pradeep K Sharma, Dr. Vikas Aggarwal, and Dr. M K Chhabrahad conceptualized the study, prepared the study protocol, conducted the data collection, analysis, and manuscript writing. Dr.

Shekhar Baweja, Dr. Rupesh Nagori, Dr. Pawan Kattihad provided key inputs on methodology during protocol preparation, supported data compilation, analysis, and manuscript writing.

\section{Reference}

01. Elganainy E, Hameed DA, Elgammal MA, Abdelsayed $A A$, Shalaby $M$. Experience with impacted upper ureteral Stones; should we abandon using semirigid ureteroscopes and pneumatic lithoclast?. Int Arch Med. 2009;2(1)13.

doi: [Article:https://doi.org/10.1186/1755-7682-213][Crossref] 
02. D'Addessi A, Francesco Bassi PF. Ureterorenoscopy- Avoiding and Managing Complications. Urol Int. 2011;87(3)251-259.

doi: [Article:https://doi.org/10.1159/000329286] [Crossref]

03. Protogerou V. Management and follow-up of impacted ureteral stones. Urol Int. $2003 ; 70(4) 269-272$.

doi: [Article:https://doi.org/10.1159/000070133] [Crossref]

04. Cho SY, Na W, Lee SW, Cho MC, Oh JJ, Lee S, et al. Medical expulsive therapy for ureter stone using naftopidil- A multicenter, randomized, double-blind, and placebo-controlled trial. PLoS ONE. 2017;12(4)e0174962.

doi:

[Article:https://doi.org/10.1371/journal.pone.017496 2][Crossref]

05. Nagae $H$. Endoscopic features of impacted ureteral stones. J Urol. 2004;171(1)89-91.

doi:

[Article:https://doi.org/10.1097/01.ju.0000100960.0 8768.81][Crossref]

06. Takahashi N, Ernst RD, Goldman SM, Benson GS, Sandier CM. Ureterolithiasis - can clinical outcome be predicted with unenhanced helical CT?. Radiol. 1998;208(1)97-102.

doi:

[Article:https://doi.org/10.1148/radiology.208.1.9646 798][Crossref]

07. Smith RC, Verga M, McCarthy SM, Rosenfield AT. Diagnosis of acute flank pain- value of unenhanced helical CT. Am J Roentgenol. $1996 ; 166(5) 97-101$.

doi:

[Article:https://doi.org/10.2214/ajr.166.1.8571915] [Crossref]

08. Feroze S, Singh B, Gojwari T, Manjeet S, Athar $B$, Hamid $H$. Role of non-contrast spiral computerized tomography in acute ureteric colic. Indian J Urol. 2007;23(2)119-121.

doi: [Article:https://doi.org/10.4103/09701591.32059][Crossref]

09. Shokeir AA, El-diasty T, Eassa W, Mosbah A, ElGhar MA, Mansour $O$, et al. Diagnosis of ureteral obstruction in patients with compromised renal function- the role of noninvasive imaging modalities. J Urol. 2004;171(6 Part 1)23032306.

doi:[Article:https://doi.org/10.1097/01.ju.0000124 928.69055.10][Crossref]
10. Elibol O, Safak KY, Buz A, Eryildirim B, Erdem K, Sarica K. Radiological noninvasive assessment of ureteral stone impaction into the ureteric wall- A critical evaluation with objective radiological parameters. Investig Clin Urol. 2017;58(5)339-345.

doi:

[Article:http://dx.doi.org/10.4111/icu.2017.58.5.339 ][Crossref]

11. Mugiya S, Ito T, Maruyama S, Hadano S, Nagae H. Endoscopic features of impacted ureteral stones. J Urol. 2004;171(1)89-91.

doi:

[Article:https://doi.org/10.1097/01.ju.0000100960.0 8768.81][Crossref]

12. Latif AMA. Ureteroscopic holmium lasertripsy for treatment of impafted ureteral calculi. Af J Urol. 2007;13(4)262-266.

Available

at

[Article:https://www.ajol.info/index.php/aju/article/vi ew/8213][Crossref]

13. Seitz C, Tanovic E, Kikic Z, Fajkovic H. Impact of stone size, location, composition, impaction, and hydronephrosis on the efficacy of HolmiumYAG-Laser Uretero lithotripsy. Europe Urol. 2007;52(6)1751-1759.

doi:

[Article:https://doi.org/10.1016/j.eururo.2007.04.02 9][Crossref]

14. Leijte JAP, Oddens JR, Lock TMTW. Holmium Laser Lithotripsy for Ureteric Calculi- Predictive Factors for Complications and Success. J Endourol. 2008;22(2)10-13.

doi: [Article:https://doi.org/10.1089/end.2007.0299] [Crossref]

15. Chandhoke R, Bamberger JN, Gallante B, Atallah W, Gupta M. Pericalculus ureteral thickness on computed tomography predicts stone impaction at the time of surgery- a prospective study. J Endourol. 2020;34(1)107-111.

doi: [Article:http://doi.org/10.1089/end.2019.0449] [Crossref]

16. Legemate JD, Wijnstok NJ, Matsuda T, Strijbos W, Erdogru T, Roth B, et al. Characteristics and outcomes of ureteroscopic treatment in 2650 patients with impacted ureteral stones. World J Urol. 2017;35(10)1497-1506.

doi: [Article:https://doi.org/10.1007/s00345-0172028-2][Crossref] 